\title{
PERCURSOS DE UMA PÓS-GRADUANDA: A DESCONSTRUÇÃO E A RESSIGNIFICAÇÃO DE CONCEITOS
}

\author{
Kathyene de Paula Fernandes ${ }^{1}$
}

RESUMO: Este artigo traz reflexões quanto ao imaginário sobre a Amazônia e da desconstrução desse imaginário como resultado dos debates promovidos pelo Programa de Pós-Graduação Linguagem e Identidade (PPGLI). As contribuições de Pizarro (2012), Stuart Hall (2016), Albuquerque Júnior (2012), Lima e Botelho (2014), Murari (2007), entre outros, se constituíram relevantes para esse processo. Algumas dessas narrativas consolidaram a visão da Amazônia brasileira como um lugar atrasado. Outras, sinalizavam a necessidade de desconstruir essa percepção. De Corrêa (2013) e Volóchinov (2017) se utiliza a reflexão acerca das questões ideológicas que se manifestam através do discurso. O que se propõe é a reflexão sobre alguns discursos já arraigados e os incômodos vivenciados nesse processo.

PALAVRAS-CHAVE: Amazônia. Narrativa. Desconstrução.

\section{INTRODUÇÃO}

O percurso formativo do sujeito do ponto de vista da escolarização é marcado pelo acesso a diversas fontes de conhecimento, quer sejam materiais ou de cunho oral, cuja intenção, ao menos discursiva, é possibilitar a construção de conceitos acerca da história e da sociedade, garantindo ao aprendiz condições de exercer criticamente a cidadania. A aprendizagem deve se constituir num processo dialógico, permitindo ao aprendiz a possibilidade de revisitar saberes e ser modificado pelo novo saber que é agregado.

Esse artigo parte das inquietações geradas por meio da disciplina: Culturas, Linguagens e Sociedades Amazônicas, ministrada aos mestrandos e doutorandos do programa de Pós-Graduação: Linguagem e Identidade. As discussões realizadas propuseram confrontos entre o que se sabia e/ou julgava saber e a assimilação de novos conhecimentos.

\section{POR ONDE COMEÇAR?}

Olhar para o ensino adquirido anteriormente e se deparar com a pouca ou insuficiente capacidade crítica gerada, do ponto de vista de formação histórica, despertou o interesse e a necessidade de revisitar e desconstruir saberes e conceitos pré-estabelecidos. Esse movimento só é possível, entretanto, mediante a realização de novas leituras e a disposição para reconhecer os equívocos e buscar desfazê-los. Refazer esse caminho não é simples, pois, nos confronta a ver o que carregamos, como carregamos e que reproduzimos tantos comportamentos preconceituosos e inferiorizadores, inclusive, desrespeitando/desvalorizando nossa própria história e cultura. A busca por respostas aos questionamentos do tipo: O que nos iguala? $\mathrm{O}$

1 Instituição: Universidade Federal do Acre, Orcid: https://orcid.org/0000-0002-8531-1136, E-mail: kathyenedepaula@bol.com.br 
que nos diferencia? Como construímos nossos saberes? E com base em quê construímos esses saberes?, revelam possíveis caminhos para pensar um processo formativo que prive pela justiça, oferecendo indícios de como a história foi sendo constituída, não se pautando apenas em uma visão colonizadora, mas também dando voz ao que foi colonizado.

É preciso destacar que, esse olhar para si e para suas construções internas não é uma tarefa fácil e requer, ao menos, a observação de três pontos cruciais: primeiro, a criticidade de reconhecer as falhas conceituais que apresentou ou ainda apresenta; segundo, a generosidade de se ver como sujeito em formação e que a sua história pode refletir um pouco das relações que estabeleceu com os outros, que também eram influenciados e assim sucessivamente, entendendo sua capacidade de transformação, no sentido de que, se agia de uma determinada maneira, num determinado momento, pode não pensar e agir da mesma maneira em outro; e, por fim, requer a coragem necessária para romper paradigmas e mudar suas práticas.

Apoiando-se nas contribuições de Albuquerque Júnior (2014), partimos do que, semanticamente a palavra saber representa na língua portuguesa. De um lado a palavra saber está associada ao sentido de conhecimento, estudo científico ou um dado sobre algo ou alguém; de outro, relaciona-se ao significado da palavra sapere de origem latina, voltando-se para seu aspecto etimológico remetendo ao sentido "ter gosto a algo ou lembrar um dado sabor" (ALBUQUERQUE JÚNIOR, 2014, p. 111). Analogamente podemos pensar na relação que o saber e o sabor podem ter entre si. Esse entendimento é fortalecido a partir da concepção que se tem sobre o conhecimento. $\mathrm{O}$ autor indicado segue afirmando que antigamente o conhecimento era concebido como algo que precisava ser saboreado. Já com a modernidade, essa possibilidade de degustação/saboreio do conhecimento perde o sentido e é sufocado pelo "imperativo da utilidade, da serventia, da praticidade, da verdade" (ALBUQUERQUE JÚNIOR, 2014, p. 112). Usamos desse argumento para propor a reflexão de que o processo de desconstrução de saberes solidificados, produzidos com base em literaturas sem um posicionamento crítico quanto a história contada a partir do olhar colonizador ou explorador, é permeada pelo sabor e dissabor que esse processo pode gerar. Sabor na perspectiva de um novo saber, atribuição de um novo sentido, do sentimento de pertença a um povo e o dissabor de se deparar e decepcionar com a visão delimitada e eurocêntrica que manteve ao longo da vida. Obviamente a postura que defendemos é a de que ainda que esse incômodo do dissabor se apresente, é necessário superá-lo para, posteriormente, gozar do saber que está sendo gerado.

\section{AS NARRATIVAS E SUA INFLUÊNCIA NA CONSTRUÇÃO DO IMAGINÁRIO AMAZÔNICO}

Albuquerque Júnior (2014) defende a importância de, pensando as narrativas historiográficas como

além de serem uma forma de saber, além de conterem um dado conhecimento, possuem em sua forma, em seu estilo, mas também, nas próprias ideias éticas e políticas que defendem ou que veiculam, mesmo inconscientemente, o que podemos chamar de um dado sabor (ALBUQUERQUE JÚNIOR, 2014, p. 126).

É necessário revisitar essa história e reescrevê-la, assumindo o sabor por tantas vezes ácido e amargo resultante do silenciamento dos povos, que se deu tanto pelo viés da tentativa de abafar as construções culturais, desvalorizando-as, ou mesmo com a destruição física dos povos em todo o processo de colonização do Brasil. 
O autor nos convida, ainda, à prática reflexiva da historiografia que tem sido praticada, não sinalizando para uma escrita azeda e/ou ressentida, mas imbuída por acabar com os excessos "de uma historiografia que privilegia a harmonia, a unidade, o encontro, a mistura, a miscigenação, a semelhança, a identidade, o arredondado, o gordo, o pesado, o lento, o viscoso, o açucarado" (ALBUQUERQUE JÚNIOR, 2014, p. 128), salientando a necessidade de recontar nossa história "despertando os paladares adormecidos" (ALBUQUERQUE JÚNIOR, 2014, p. 128), permitindo problematizar conceitos tão difundidos e fortalecidos a partir

da construção de um discurso historiográfico áspero, seco, que não seja fácil de ser tragado, que incomode a quem lê e a quem produz [...] que nos retire do nosso conforto [...] que traga para a cena os eventos e personagens que foram feridos, magoados, que doloridos viveram vidas de resto e de rastro (ALBUQUERQUE JÚNIOR, 2014, p. 129).

Como ponto de partida, entendemos a indispensabilidade de discutir alguns conceitos que estão diretamente relacionados à percepção de como processamos as questões históricas. Iniciamos refletindo sobre o que compreendemos por cultura e como ela se processa em nós e através de nós.

Stuart Hall (2016) explica que, por cultura, podemos compreender um conjunto de práticas em que os sujeitos compartilham significados, ou seja, atribuem sentido à algo. Isso implica o sentimento de pertença, de fortalecimento identitário. "Os significados culturais não estão somente na nossa cabeça - eles organizam e regulam práticas sociais, influenciam nossa conduta e, consequentemente, geram efeitos reais e práticos" (HALL, 2016, p. 20). O autor assegura que as coisas que tem sentido, só o tem porque atribuímos a ela significados, interpretações; e que esse sentido é produzido e influenciado pelas práticas cotidianas exteriorizadas no circuito cultural: "na construção da identidade e na demarcação das diferenças, na produção e consumo, bem como na regulação da conduta social [...] e um dos 'meios' privilegiados através do qual o sentido se vê elaborado e perpassado é a linguagem" (HALL, 2016, p. 22). Nessa perspectiva, o entendimento de linguagem não está relacionado apenas à fala ou à escrita, mas refere-se a todos os modos de representação, ou seja, as práticas que são utilizadas para demonstrar ou significar o que sentimos ou pensamos. A "representação é uma parte essencial do processo pelo qual os significados são produzidos e compartilhados entre os membros de uma cultura. Representar envolve o uso da linguagem, de signos e imagens que significam ou representam objetos" (HALL, 2016, p. 31).

Admitindo que a população brasileira é formada predominantemente por sujeitos advindos de vários lugares sendo, portanto, heterogênea e, considerando que a representação de uma determinada cultura é o que tem sentido/significado para os sujeitos que compartilham certas práticas, não é possível pensar numa homogeneidade cultural. A cultura envolve interpretações que não podem ser generalizadas, logo não há como estabelecer a perspectiva de uma verdade absoluta, uma vez que "interpretações são sempre seguidas por outras interpretações, em uma cadeia infinita" (HALL, 2016, p. 77).

Stuart Hall (2016) destaca, ainda, um aspecto importante sobre a linguagem quando ressalta que, mesmo que por meio dela se tenham indícios culturais, há situações em que determinadas pessoas tem mais autonomia ou credibilidade para abordar determinados as- 
suntos do que outras, o que sinaliza que existem relações de conhecimento e poder que devem ser ponderadas.

Esse aspecto aponta para outro elemento importante para os estudos culturais: a constituição do discurso como crucial no papel da representação. Stuart Hall (2016) apoia-se nas explicações de Foucault quando este entende o discurso como um sistema de representação que constrói sentidos por meio da linguagem, associando-a com a prática social. O discurso, nesse entendimento,

define e produz os objetos do nosso conhecimento, governa a forma com que o assunto pode ser significativamente falado e debatido, e também influencia como ideias são postas em prática e usadas para regular a conduta dos outros. Assim como o discurso 'rege' certas formas de falar sobre um assunto, definindo um modo de falar, escrever ou se dirigir a esse tema de forma aceitável e inteligível, então também, por definição, ela 'exclui', limita e restringe outros modelos (HALL, 2016, p. 80).

É preciso destacar, também, que Stuart Hall (2016) afirma que esse discurso se modifica com o tempo e que práticas defendidas num determinado período podem sequer fazer sentido em outro.

Outro aspecto importante acerca da cultura é que "ao longo da história, a noção de cultura teve diversos significados e matizes" (VARGAS LLOSA, 2013, p. 35), isso implica dizer que a concepção de cultura sofreu modificações e que o que antes se compreendia como elemento cultural, pode não o significar mais. Por um período a cultura estava associada à questão do saber, nesse entendimento havia as pessoas ditas cultas, que dominavam certos saberes e gozavam de prestígio social por isso e as consideradas incultas, que não apresentavam esses mesmos requisitos. "Essa classificação era bastante clara para o mundo inteiro porque para todos vigorava um mesmo sistema de valores, critérios culturais e maneiras de pensar, julgar e comportar-se" (VARGAS LLOSA, 2013, p. 35).

Vargas Llosa (2013) ressalta que devido à ampliação da noção/compreensão da cultura, a mesma apagou-se, sob o entendimento de que não haverá mais sujeitos cultos, se por cultura se aceitar situações degradantes. O autor segue dizendo que o início de toda essa compreensão epistemológica foi impulsionado pelos antropólogos que "estabeleceram que cultura é a soma de crenças, conhecimentos linguagens, costumes, indumentária, usos, sistemas de parentesco, em resumo, tudo o que um povo diz, faz, teme ou adora" (VARGAS LLOSA, 2013, p. 35).

Outra discussão importante, que também se relaciona com a necessidade de repensar sobre alguns conceitos que estabelecemos, tem a ver com a visão que temos da Amazônia. É importante ressaltar o entendimento de Pizarro (2012) quando afirma que
a Amazônia é uma construção discursiva. Somente através dessa construção é possí- vel chegar à sua imagem. Esta região do imaginário é a história dos discursos que a foram erigindo, em diferentes momentos históricos, dos quais recebemos apenas uma versão parcial, a do dominador" (PIZARRO, 2012, p. 33)

Ou seja, o modo como nos vemos e percebemos nosso lugar é sim atravessado por diversas concepções e que estas podem ter sido induzidas por certos sujeitos que, por advirem de outras localidades, com características diferentes das observadas na Amazônia, não entendem ou não valorizam determinadas especificidades dessa região. 
Para uns a Amazônia é quase que como uma entidade sagrada, que domina o homem, submetido às suas forças, sendo como Euclides da Cunha afirma "um intruso impertinente" (CUNHA, 1999, p. 01). Aqui a verdade é a de que o sujeito nada mais pode a não ser se submeter e aceitar o que a força amazônica representa, não no sentido representativo, mas literal.

Lima e Botelho (2014) argumentam que os relatos de Cunha reforçam a fragilidade do homem em relação à natureza e afirmam ele que chegou a ficar decepcionado pois esperava que alguns elementos que a constituem fossem mais grandiosos do que, no seu ponto de vista, se apresentaram. Na sua visão, essa natureza é marcada pela monotonia, sem consideráveis alterações ou surpresas, em contrapartida, temos o homem marcado pelo nomadismo, não fixando raízes, mas indo de um lugar para o outro buscando sua subsistência. Ao narrar a saga do Judas Ahsverus, em sua obra: À margem da História, Euclides da Cunha, compara esse personagem ao imigrante que deixou sua terra e se submeteu às condições de vida na Amazônia em virtude de sua ambição, incluindo o sofrimento que algumas doenças tropicais, como a malária, podem causar.

Murari (2007), ao analisar a obra Os sertões de Euclides da Cunha, argumenta que a intenção desta narrativa era vingadora, no sentido de propor uma reflexão do Brasil esquecido ou não sabido e a maior causa disso é tanto o desinteresse quanto a falta de conhecimentos referentes ao espaço em que o homem ocupa, ao próprio homem e a história. As narrativas de Cunha, segundo a autora, definem o sertão como marcado pela imobilidade, monotonia, com características espaciais e geográficas que minimizam a capacidade humana de modificar a realidade posta, "é um espaço alheio à história, ou pelo menos a uma concepção de história centrada no fluxo das rápidas transformações tecnológicas e sociais engendradas pela modernidade" (MURARI, 2007, p. 50). Assim, o principal agente que poderia mudar a realidade atrasada do sertão é o homem civilizado, pois já desenvolveu saberes pautados na ciência e na tecnologia.

Murari (2007) explica que, com a tentativa de preceder a um estudo geográfico do Brasil e também dos aspectos referentes ao progresso do país, as expectativas se voltaram para os centros urbanos, deixando desapercebidos as especificidades do interior que passaram a ser estudadas por estrangeiros que as trataram com indiferença. Essa situação favoreceu a construção de uma história brasileira excessivamente a partir de uma interpretação dos estrangeiros. A autora explica que Cunha defende que é imprescindível que se modifique essa prática, além da necessidade de "relativizar o legado dos viajantes. Segundo ele, seu engrandecimento teria sido favorecido pelo silêncio dos brasileiros a respeito de seu próprio país" (MURARI, 2007, p. 55). Há uma predisposição em acreditar que o olhar do estrangeiro sobre a terra que visita é marcado pela neutralidade e desinteresse, Murari (2007) ressalta, entretanto, que aliado ao "conhecimento científico que produz e transmite, o viajante frequentemente interpreta sua própria existência. O significado da viagem não é, e nem poderia ser, apenas científico" (MURARI, 2007, p. 58-59).

Destaca-se que os conhecimentos históricos produzidos, dos quais os brasileiros tomavam como seus, não foram construídos apenas por estrangeiros. O instituto Histórico e Geográfico Brasileiro realizou viagens com o intuito de traçar um perfil nacional, objetivando atribuir-lhe uma identidade. Murari (2007) pondera que, aliado a isso, havia também a observação do que economicamente se configurava viável, pontuando o que seria vantajoso para 
a nação. A autora afirma que o fantasioso e exagerado imaginário sobre a natureza brasileira também é estimulado por autores brasileiros que criam estereótipos, numa espécie de auto-exotismo.

Há várias perspectivas que influenciam as concepções sobre a Amazônia e essas perspectivas são perpassadas pela história do sujeito que a descreve.

\begin{abstract}
Eldorado dos aventureiros, celeiro do mundo capitalista, inferno verde dos naturalistas e paraíso perdido dos poetas, mundo selvagem e pulmão do mundo, a Amazônia foi, e continua sendo, cantada e decantada, romântica e cientificamente, por viajantes estudiosos, por artistas e políticos, ao longo dos anos. Foi louvada, amaldiçoada e chorada em verso e prosa. Foi percorrida, penetrada, pisada e mal interpretada por 'quadrilha' de turistas (COSTA, 2016, p. 92).
\end{abstract}

Os autores Lima e Botelho (2014) apontam que existem contradições, por exemplo, nas narrativas de Euclides da Cunha, pois ao passo que ele ajudava na compreensão de uma imagem da natureza enquanto um enigma que precisava ser explicado mediante a ciência e da sociedade que precisava ser salva pelo sujeito 'civilizado e superior', também tece críticas ao que denominou como "visões fantasiosas" (LIMA; BOTELHO, 2014, p. 141) apresentadas por alguns escritores naturalistas nos séculos XVIII e XIX.

Lima e Botelho (2014) se debruçam sobre os relatos de duas viagens realizadas por Carlos Chagas e Mário de Andrade, claramente com objetivos diferentes e que também ajudam a construir um imaginário acerca da Amazônia. A primeira viagem é a de Carlos Chagas, que defendeu a necessidade de se pensar sobre as questões higiênicas que foram observadas, as doenças características da região amazônica e sua integralização ao Brasil a partir de um projeto civilizatório. A viagem de Mário de Andrade, que resultou, posteriormente, na obra: O turista aprendiz, publicado quase 50 anos após sua realização, tinha o cunho turístico e, sendo este um modernista, sempre estava às voltas com "temas relativos à civilização brasileira, tradição e modernidade, autenticidade e tradução cultural, além de seus pressupostos reflexivamente confrontados com o mundo que vai descobrindo" (LIMA; BOTELHO, 2014, p. 159). Os dois viajantes citados leram Euclides da Cunha e como ponto comum em seus relatos há "as relações entre malária e a possibilidade de constituir uma civilização nos trópicos" (LIMA; BOTELHO, 2014, p. 143).

Nos relatos de Carlos Chagas, a partir da análise de Lima e Botelho (2014), o desenvolvimento dos trópicos seria possível a partir de uma medicina que civilizaria os sertões, indicando a trilha do progresso econômico: o combate à malária que era uma das doenças que afetava a produtividade dos seringueiros, o que causava prejuízo econômico devido à queda da produção da borracha. Chagas entende sua viagem com um propósito específico de salvação, ação redentora associada à medicina, buscando estudar sobre a malária e obter novas informações acerca de uma nova doença descoberta.

É necessário ressaltar que o Instituto Oswaldo Cruz também teve relevância para o desenvolvimento da medicina nos trópicos, realizando viagens tanto para fins de levantamento de matérias para o incremento de pesquisas quanto a realização de expedições objetivando propor medidas que favorecessem o saneamento da região e, consequentemente, a extinção da malária. 
Lima e Botelho (2014) destacam que os estudos científicos realizados através das missões ampliaram os conhecimentos acerca dos mosquitos e das doenças e, com isso, enriqueceram as linhas de pesquisas, uma vez possibilitaram que um acervo maior e diverso fosse construído e os relatórios resultantes dessas ações apontavam, não apenas as questões propriamente científicas mas também expunham as condições de saúde, de trabalho e de vida de um modo geral a que a população estava sujeita.

Os autores afirmam que os povos indígenas são vistos, nos relatos de Chagas, sob uma ótica desprovida de empatia sendo descritos como feios e preguiçosos e, devido à sua inferioridade, são explorados pelos brancos. Chagas indica que a solução para povoar a região amazônica é que os sertanejos migrassem para esse espaço.

Ainda sobre as considerações de Lima e Botelho (2014), nos relatos de Mário de Andrade há uma tentativa de desconstrução, através da ironia, da percepção do atraso tropical e o entendimento de que a civilização só é possível a partir da profilaxia da malária. Andrade busca também, descategorizar alguns elementos amazônicos construídos por narrativas como as de Euclides da Cunha, que propõem certo encantamento aliado a visão exótica da Amazônia. Ainda que Mário de Andrade até utilize termos como os de Euclides da Cunha, o faz buscando contrapor-se "à ideia de exotismo associada à de exuberância da própria natureza, cuja contrapartida, no imaginário sobre a Amazônia, tem sido quase sempre a ideia da fragilidade do homem, a que nem mesmo Euclides fugiu inteiramente" (LIMA; BOTELHO, 2014, p. 167). Assim, os autores indicam a relativização imposta por Mário de Andrade quando este afirma preferir ficar com o imaginário dos livros, mas não se voltando inteiramente para ele, buscando refletir os elementos naturais vistos como exuberantes e monótonos, dependendo do tempo, focando mais na diversidade das práticas diárias das comunidades e em suas tantas histórias, contrapondo-se ao discurso da falta de história do povo amazônico de Euclides da Cunha.

Lima e Botelho (2014) afirmam que Mário de Andrade busca superar a visão da discrepância entre a natureza enquanto elemento superior e mais forte do que o homem, tido por Cunha como um sujeito frágil e submetido as forças naturais. Os autores afirmam que as

$$
\begin{aligned}
& \text { representações euclidianas da Amazônia, porém, não são simplesmente confronta- } \\
& \text { das e ainda menos descartadas por Mário de Andrade [...]. Forma-se, antes um diá- } \\
& \text { logo denso, nem sempre nomeado, por dentro dos tropos há muito construídos sobre } \\
& \text { a Amazônia na chave do real-maravilhoso naturalista de Euclides e outros seguidores } \\
& \text { e expressionistamente transfigurado em Mário (LIMA; BOTELHO, 2014, p. 169). }
\end{aligned}
$$

Andrade (2015) ao descrever sua viagem pela região amazônica buscou pensar sobre os sujeitos e as relações que estabeleciam bem como os elementos naturais vislumbrados ao longo do percurso, observando a música, o artesanato, a linguística, as danças, a alimentação, se predispondo às relações de alteridade, procurando conhecer e respeitar o outro. Afirma que não tem compromisso em descrever apenas elementos reais, mas em suas narrativas inclui elementos irreais, admitindo ainda que já tinha algumas impressões de como seria a Amazônia, fruto de suas leituras anteriores, mas busca se distanciar de uma série de visões depreciativas sobre a Amazônia, bem como do discurso sobre as relações estabelecidas. Há a tentativa de resistir a um olhar imperial, que se funda na ideia da Amazônia a partir de uma visão externa, dos povos considerados civilizados a despeito do povo amazônico, tido como 
incivilizado, inferior. Andrade (2015), inclusive, ironiza a Carta de Pero Vaz de Caminha no trecho em que relata o encontro com os indígenas sugerindo que quem teve medo dos viajantes foram os indígenas e não o contrário, como supõe a carta indicada. Em seus escritos há trechos que apresentam invenção e humor. Em muitos momentos ele mesmo caçoa de algumas ideias que tinha da Amazônia. Apresentou concepções culturais mais democráticas, se disponibilizando a desconstruir seu olhar para tentar visualizar outros lugares, de outras formas. Propõe, também, a um abrasileiramento, no sentido da necessidade de conhecer os diversos brasis existentes.

Nesse sentido, também podemos citar o conde Ermanno Stradelli, que sempre buscou em sua obra, estabelecer um diálogo entre os conhecimentos que já trazia de seu continente e os conhecimentos adquiridos no continente em observação. Costa (2016) afirma que, por meio de suas notas de viagem, de suas fotos e desenhos, Stradelli compartilha "sua sabedoria e sua angústia e nos oferece uma possibilidade de compreensão de momentos históricos da região" (COSTA, 2016, p. 110), o que indica que não há a postura de um olhar colonizador, mas do sujeito que busca considerar os vários pontos que explicam determinadas práticas.

Ainda que Stradelli não tenha tido uma visibilidade mais ampla no próprio Brasil, diz Costa (2016), suas contribuições impulsionaram uma reflexão mais aprofundada diante do que já tinha sido dito sobre a cultura e os povos que aqui viviam. Através das imagens capturadas pelo conde, a chamada imagética de Stradelli, é possível afirmar que seu interesse era falar "de vida, de desequilíbrio ambiental, de convivência amistosa com a natureza, de respeito à alteridade. São fotos de povos, gentes, rios e florestas e, sobretudo, da presença humana na região. Região que se urbanizava e se urbaniza rapidamente" (COSTA, 2016, p. 113).

A autora segue afirmando que o estabelecimento desse olhar mais dialógico, também é fruto da vivência de Stradelli na região observada, superando a visão de exotismo que muitos viajantes apresentaram, o que demonstrou "um quadro conceitual aberto para pensar a realidade local" (COSTA, 2016, p. 127). A apropriação da língua e de algumas expressões favoreceram a ele um aprofundamento nas maneiras de compreender as manifestações dos sujeitos observados, tanto do ponto de vista da fala quanto da manifestação mental. O trabalho desenvolvido, através de suas imagens revelam ainda, que possuía, além da sensibilidade para pensar o sujeito, conhecimento da tecnologia, da etnografia e de estética.

Murari (2007) aponta também outros autores que tem sua importância na construção ou desconstrução do imaginário sobre a Amazônia brasileira. Cita Humboldt que produz mudanças sobre as narrativas de alguns viajantes que focavam na catalogação e descrição dos elementos possíveis de um lugar, tentando retratar a geografia do espaço em visitação. Humboldt busca induzir a consciência da natureza "não como objeto passivo a ser coletado e catalogado, mas como espetáculo dramático e grandioso que superava a capacidade humana de compreensão racional" (MURARI, 2007, p. 64), defendendo que o homem, ao se relacionar com a natureza, não apenas influencia, mas é, também, influenciado por ela.

Apoiando-se nas ideias de Buckle, um teórico que estudou sobre as questões geográficas do Brasil apresentando sua compreensão acerca do 'atraso' brasileiro, Murari (2007) explica a ação humana pode ser determinada com base na natureza, indicando quatro fatores físicos que influenciam a conduta do homem: "o clima, o alimento, o solo e o aspecto geral da natureza" (MURARI, 2007, p. 69), podendo causar também impedimentos para o progresso. 
Assim, para o desenvolvimento econômico e social de um país, é necessário que se articulem as potencialidades naturais e humanas. Tal entendimento aponta uma problemática para o povo sertanejo, uma vez que o clima quente e alguns aspectos geográficos o deixaria menos produtivo, logo refletiria no progresso daquela região.

Entendendo a diversidade geográfica e cultural que o Brasil apresenta, Nenevé e Sampaio (2015) ressaltam o entendimento de que não devemos falar em Amazônia no singular, assim como também não podemos conceber cultura como um elemento universal. Os autores enfatizam a necessidade de mudar o entendimento que se tem sobre a Amazônia, como se houvesse uma única maneira de compreendê-la, sendo caracterizada por um único viés constitutivo. É superar a visão homogênea que coloca todos os sujeitos que nela e dela se formam, desfazendo o ideário de uma cultura que envolve ou abarca todos os seres, como se manifestassem as mesmas crenças e percepções de si mesmo e do seu povo. É necessário extrapolar os

\begin{abstract}
discursos que não se preocupam muito em discutir a enorme diversidade nem a dinâmica das culturas que povoam a Amazônia. Sim, existem povos indígenas, existem sistemas antigos de povoamentos pré-colombianos, como também existe uma Amazônia multiétnica, multicultural, que passa por uma mudança dinâmica. Há a Amazônia urbana como há um amplo conjunto de comunidades isoladas. São histórias heterogêneas, conhecimentos científicos variados, intersecção de histórias indígenas com a dos colonizadores, produção de conhecimento que parte da própria região e dos próprios povos que a habitam (NENEVÉ; SAMPAIO, 2015, p. 20)
\end{abstract}

Nenevé e Sampaio (2015) afirmam a necessidade de se reimaginar a Amazônia em que "redizer e desdizer, significa ressignificar e repensar as definições e conceitos sobre o local [...]. Ainda hoje muitas vozes são apagadas, desvirtuadas, aniquiladas ou negligenciadas porque o que se ouve são rumores externos que se impõem sobre os internos" (NENEVÉ; SAMPAIO, 2015, p. 21). É um olhar para dentro, não aceitando puramente o que dizem sobre nós, mas refletindo sobre o que aceitamos que digam sobre nós.

Numerosas escritas sobre a Amazônia não explicitam, de fato, as relações e saberes que se manifestam nessa região, primeiramente por que quem escreve, escreve a partir de um ponto de vista que é influenciado por sua própria história de vida, por seus conceitos, por suas representações e por seus conhecimentos já constituídos e influenciados por outros sujeitos que também são influenciados por outras histórias e assim por diante. Justamente por isso, tantos escritos sempre minimizam e inferiorizam as pessoas, os saberes e os costumes dos sujeitos denominados amazônicos. Partem de suas próprias representações do que é civilização e desenvolvimento e, nessa falta de esforço de considerar o que se encontra, se julga como superior e detentor do progresso e da proteção a que o sujeito dominado necessita.

Muitos autores que se debruçaram na tentativa de descrever a Amazônia, o fizeram com a intenção de mostrar-se salvador, mantendo a visão colonizadora e libertadora da condição de incivilizado e atrasado do dominado. Antes de realizarem as viagens que, teoricamente, os dariam argumentos para discorrer sobre os aspectos que fundamentam nossas culturas, esses pesquisadores se voltaram para estudos que trazem arraigadas algumas percepções que não consideram as vivências do próprio sujeito e não valorizam os conhecimentos locais produzidos por aqueles que se fizeram nesses espaços. Ainda há uma infeliz prática de, nas palavras de Nenevé e Sampaio (2015), valorizar os escritos de autores de outras regiões e, especialmen- 
te, de outros países, como se estes tivessem muito mais propriedade para falarem sobre nós do que nós mesmos. Há uma cultura de submissão e subordinação que sempre nos diminui e que precisa ser vencida.

Nosso argumento, portanto, é que é necessário descolonizar esse conhecimento. Precisamos ouvir vozes locais, prestar atenção nas pesquisas que são feitas por estudiosos da região, dialogando com a grande diversidade de perspectivas, pontos de vistas e interpretações dos mesmos [...]. O que assusta é quando nós estudantes, pesquisadores e professores, renegamos ou ignoramos o que tem sido produzido por aqui em termos de conhecimento e em literatura (NENEVÉ; SAMPAIO, 2015, p. 29).

Ishii (2016) aponta que muito do que temos na literatura é resultado das narrativas de viajantes que, partindo do seu ponto de interesse, descreviam os aspectos que julgavam mais pertinentes, logo, "pode-se dizer que as impressões do viajante são marcadas pelo olhar que classifica, enquadra, descreve e analisa o que vê. Seus olhos possuem lentes que filtram o olhar" (ISHII, 2016, p. 153), e nesse filtro, o sujeito é silenciado, tendo sua identidade emoldurada e encerrada a partir de um olhar colonizador que não considera as várias nuances que constituem tanto o sujeito quanto os próprios locais em que estes sujeitos estão inseridos. Nessa perspectiva, "os locais não falarão, serão falados" (ISHII, 2016, p. 156).

Além disso, as percepções que levavam a defesa imoral de práticas discriminatórias e de subjugação do sujeito, por exemplo as que sofreram os negros e índios da América, baseadas nos "maus tratos e a domesticação" por serem considerados como "sub-humanos ou semi-animais", justificavam-se como forma de "técnicas para a subordinação social" (ISHII, 2016, p. 157). Ao silenciar esse sujeito, sob o argumento de sua incivilidade que se fundamenta por apresentar práticas contrárias à cultura do que descreve, o viajante busca indicar caminhos para superar as 'faltas' que esse indivíduo apresenta, como se o que escreve tivesse condições morais e intelectuais para tirar esse sujeito dominado de sua condição de inculto. É importante salientar que as compreensões produzidas por meio dessas narrativas geográficas continuam incentivando esse olhar equivocado sobre os sujeitos e

\footnotetext{
continua a colaborar, ainda nos dias de hoje, com os silenciamentos e discursos de invenção e conquista da região. Uma "região" para a qual o projeto imperial "moderno" previa - e prevê - a permanente exploração da natureza, concomitantemente à exploração e ao não reconhecimento das práticas e modos de vidas de suas populações (ISHII, 2016, p. 162).
}

Nessa perspectiva podemos discutir também sobre o preconceito que os sujeitos que moram em uma determinada localidade sofrem, exclusivamente, por pertencer àquele lugar. Inicialmente é importante esclarecer, conforme as compreensões de Albuquerque Júnior (2012), que o preconceito se refere a um conceito antecipado sobre algo ou alguém, é uma concepção que precede a qualquer tipo de relacionamento, é um olhar para o outro a partir de crenças ou percepções pessoais, por isso é fácil entender que a prática preconceituosa fala mais sobre o que a utiliza do que o que sofre a ofensa.

Sobre o preconceito quanto a origem geográfica

é justamente aquele que marca alguém pelo simples fato de pertencer ou advir de um território, de um espaço, de um lugar [...] de um continente considerado por outro ou 
outra, quase sempre mais poderoso ou poderosa, como sendo inferior, rústico, bárbaro, selvagem, atrasado, subdesenvolvido (ALBUQUERQUE JÚNIOR, 2012, p. 11)

Em muitos casos, o preconceito aparece disfarçado num discurso que é carregado de ironia e 'boas intenções'. As famosas brincadeirinhas bobas que, para o que diz, não tem peso nenhuma, mas para o que escuta, machuca e inferioriza. A angústia é que, mesmo com tantos debates a respeito do tema, ainda é real e constante a prática de comportamento e discursos preconceituosos. Para muitos, falta empatia e respeito, não se preocupando com o que aflige ou incomoda o outro, como se o que fala tivesse direito sobre o que ouve. É o que Albuquerque Júnior (2012) argumenta quanto a prática de nomear algo ou alguém. Quando nomeamos é como se tivéssemos poder para dizer o que o outro é, o que deve ser ou fazer. Nomear envolve o sentido de definir e essa definição pode incluir o entendimento do que serve ou não, do que é bom ou não, mas sempre numa perspectiva unilateral em que o que nomeia, o faz partir de suas próprias convicções, silenciando o que é nomeado e reduzindo-o às suas próprias expectativas.

\section{CONSIDERAÇÕES FINAIS}

Ao longo das leituras e debates propostas no mestrado ofertado no Programa de Pós-graduação em Linguagem e Identidade da Universidade Federal do Acre houveram muitos momentos em que os acadêmicos foram motivados a confrontar suas percepções e condutas, buscando identificar práticas preconceituosas cultivadas pela falta de reflexão crítica e de um direcionamento que confrontasse o saber que julgavam "correto".

À medida que foram discutidas bibliografias de autores que escreveram e defenderam concepções distintas sobre o processo de colonização da região amazônica, percebemos modos de ser e fazer, por vezes escondidos sob a 'boa intenção' de tornar algo ou alguém conhecido, possibilitando a reflexão e a ressignificação de conceitos e representações que carregamos em nossa trajetória de vida.

Olhar para si tende a ser difícil e o é mais ainda quando entendemos que nossa sabedoria, não traz em si todos os vieses que constituem a história, aliás, a verdade é algo que passa a ser questionada, uma vez que o que um toma por verdade pode não ser para o outro, ou seja, a verdade também passa a ser uma representação do sentido que damos a algo ou alguém.

Além disso, refletir sobre essas concepções implica o surgimento de outras angústias, no que pese a compreensão da necessidade de que essas discussões precisam extrapolar os muros das academias e chegar a todos os sujeitos. O povo precisa ter o entendimento da riqueza da sua diversidade cultural e histórica, justamente para que não se submeta e/ou continue aceitando que situações constrangedoras que revelam a ignorância e desrespeito quanto à sua história. E o propósito não é criar embates, mas é "alargar nossa visão e percepção, dilatar nossos olhares a fim de que possamos considerar muitas outras obras e muitas outras visões e percepções" (NENEVÉ; SAMPAIO, 2015, p. 32-33).

Mesmo considerando a diversidade que caracteriza a constituição populacional do Brasil e tendo a perspectiva de que toda essa variedade deveria promover a superação de práticas discriminatórias e reducionistas, estudos sociais apontam que ainda há um longo caminho a percorrer. É uma problemática que precisa ser modificada e só o será quando, de fato, nos de- 
bruçarmos para conhecer e respeitar a história dos diversos grupos culturais que fazem desta nação, tão rica e heterogênea.

\section{A GRADUATE STUDENT'S PATHWAYS: DECONSTRUCTION AND REFRAMING OF CONCEPTS}

ABSTRACT: This article brings reflections on the imaginary about the Amazon and the deconstruction of that imaginary as a result of the debates promoted by the Language and Identity Graduate Program (PPGLI). The contributions of Pizarro (2012), Stuart Hall (2016), Albuquerque Júnior (2012), Lima and Botelho (2014), Murari (2007), among others, were relevant to this process. Some of these narratives consolidated the vision of the Brazilian Amazon as a backward place. Others signaled the need to deconstruct this perception. De Corrêa (2013) and Volóchinov (2017) use the reflection on the ideological issues that are manifested through the discourse. What is proposed is a reflection on some speeches that are already ingrained and the discomfort experienced in this process.

KEYWORDS: Amazon. Narrative. Deconstruction.

\section{REFERÊNCIAS}

ALBUQUERQUE JUNIOR, Durval Muniz. Por uma história acre: saberes e sabores da escrita historiográfica. In: ALBUQUERQUE, G. R. e ANTONACCI, M. A. Desde as Amazônias Colóquios (volume 2). Rio Branco (AC): Nepan Editora, 2014.

ALBUQUERQUE JUNIOR, Durval Muniz. Preconceito contra a origem geográfica e de lugar: as fronteiras da discórdia. São Paulo: Cortez, 2012.

ANDRADE, Mário. O turista aprendiz. Brasília, DF: Iphan, 2015.

COSTA, Selda Vale da. "Imagens da Amazônia: Ermanno Stradelli", pp. 89-129. In: BASTOS, Elide Rugai \& PINTO, Renan Freitas (orgs.). Vozes da Amazônia III. Manaus: Valer/Edua, 2016.

CUNHA, Euclides. À Margem da História. São Paulo: Martins Fontes, 1999.

HALL, Stuart. Cultura e representação. Tradução de Daniel Miranda e William Oliveira. Rio de Janeiro: Ed. PUC-Rio: Apicuri, 2016.

ISHII, Raquel Alves. Silenciamentos e discursos da conquista: Henry Bates e expedições científicas na Amazônia do século XIX. In: ALBUQUERQUE, Gerson (org.). Das margens. Rio Branco: Nepan Editora, 2016, 225 p.

NENEVÉ, Miguel; SAMPAIO, S. m. G. Re-imaginar a Amazônia, descolonizar a escrita sobre a região. In: ALBUQUERQUE, Gerson Rodrigues de (orgs.). Literaturas e Amazônias: colonização e descolonização. Rio Branco: Nepan Editora, 2015, 288 p.

MURARI, Luciana. Brasil, ficção geográfica: ciência e nacionalidade no país d'Os Sertões. Annablume: Belo Horizonte, 2007.

PIZARRO, A. Amazônia: as vozes do rio: imaginário e modernização. Tradução: Rômulo Monte Alto. Belo Horizonte: Editora UFMG, 2012.

VARGAS LLOSA, Mario. A civilização do espetáculo: uma radiografia do nosso tempo e da nossa cultura. 1. ed. - Rio de Janeiro: Objetiva, 2013. 